\title{
Purification, Characterization, Crystallization, and Preliminary X-Ray Results From Paracoccus denitrificans Porin
}

\author{
Andreas Hirsch, ${ }^{1}$ Thomas Wacker, ${ }^{1}$ Jürgen Weckesser, ${ }^{2}$ Kay Diederichs, ${ }^{1}$ and Wolfram Welte ${ }^{3}$ \\ ${ }^{1}$ Institut für Biophysik und Strahlenbiologie, 79104 Freiburg, Germany; ${ }^{2}$ Institut für Biologie II, Mikrobiologie, \\ 79104 Freiburg, Germany; and ${ }^{3}$ Universität Konstanz, Fakultät für Biologie, 78434 Konstanz, Germany
}

\begin{abstract}
The porin from Paracoccus denitrificans ATCC 13543 was purified and crystallized. Two crystal forms were obtained from porin solutions with $\beta$ - $d$-octylglucopyranoside as detergent. Crystals of form I belong to the monoclinic spacegroup $C 2$ with unit cell dimensions $a=112.2 \AA, b=193.8 \AA, c=100.5 \AA$ and $\beta=129.2^{\circ}$. There is 1 trimer per asymmetric unit. Crystals of form II are triclinic with $a=$ $89.7 \AA, b=98.8 \AA, c=112.5 \AA, \alpha=112.5^{\circ}, \beta=$ $101.8^{\circ}, \gamma=106.7^{\circ}(2$ trimers per asymmetric unit). Both crystal forms diffract to $3 \AA$. (c) 1995 Wiley-Liss, Inc.
\end{abstract}

Key words: crystals, membrane protein, outer membrane, X-ray diffraction

\section{INTRODUCTION}

Porins are channel-forming proteins that span the outer membrane of Gram-negative organisms allowing the diffusion of small polar solutes across the membrane. ${ }^{1}$ In general, bacterial porins are organized as trimers. Structure analysis of porin from $R$ hodobacter capsulatus showed that the polypeptide chain of each subunit traverses the membrane 16 times as antiparallel $\beta$-strands forming a large barrel. $^{2}$ Each subunit forms one channel; the trimer therefore contains three channels. The same architecture was observed for porins $\mathrm{OmpF}$ and $\mathrm{PhoE}$ from $E . c o l i^{3}$ and the porin from Rhodopseudomonas blastica. ${ }^{4}$ Maltoporin differs from the nonspecific porins by containing an 18-stranded barrel. ${ }^{5}$

A transmembrane channel may be considered as the common structural motif of ionic channels from bacterial and eukaryotic membranes. ${ }^{6}$ While the outer membrane porins are made up of amphiphilic $\beta$-strands, the transmembrane domains of plasma membrane transporters generally consist of hydrophobic $\alpha$-helices, often representing a $6+6$ helix architecture. ${ }^{7}$ However, in eukaryotic cells the $\beta$-barrel design has been identified in at least one channel family, the mitochondrial porin, which forms large, open channels in the mitochondrial outer membrane. ${ }^{8}$ This is significant, as these organelles are considered descendants of bacterial symbionts.
In view of the endosymbiontic hypothesis of the evolutionary origin of mitochondria Paracoccus denitrificans occupies a unique position. It displays the most mitochondrial features compared with other aerobic bacteria ${ }^{9}$ and has been described in literature as "free living mitochondrion" or "protomitochondrion." 10 In contrast to the general trimeric organisation of bacterial porins, the porin of Paracoccus denitrificans was originally described as a dimer. ${ }^{11}$ Here we report the crystallization of the Paracoccus porin.

\section{Purification}

\section{MATERIALS AND METHODS}

Porin was purified from Paracoccus denitrificans ATCC 13543 according to a modified procedure. ${ }^{11}$ Cells were broken by passage through a French pressure cell. The resulting homogenate was centrifuged at $160,000 \mathrm{~g}$ for $45 \mathrm{~min}$. In order to remove the inner membrane and some outer membrane proteins, the membrane pellets were treated with a buffer solution containing $20 \mathrm{mM}$ Tris- $\mathrm{HCl}(\mathrm{pH} 8.0)$, $1 \mathrm{mM}$ EDTA, $2 \%$ SDS, $35^{\circ} \mathrm{C}$ for $30 \mathrm{~min}$. The pellet of the centrifugation step contained primarily porin bound to peptidoglycan. The porin was solubilized with Tris-HCl buffer ( $\mathrm{pH} 8.0$ ), containing $1 \mathrm{mM}$ EDTA, $500 \mathrm{mM} \mathrm{NaCl}$, and $2 \%$ of the detergent lauryl-(dimethyl)-amine oxide (LDAO), at $30^{\circ} \mathrm{C}$ for 60 min. The insoluble material was removed by another centrifugation step.

Further purification was achieved by anion exchange chromatography using Q-Sepharose (Pharmacia). After removing of $\mathrm{NaCl}$ by dialysis, the porin solubilisate was applied to a column, equilibrated with $20 \mathrm{mM}$ Tris-HCl (pH 8.0), $1 \%$ (w/v) LDAO. Upon applying a linear $\mathrm{NaCl}$ gradient in the same buffer, porin eluted at $700 \mathrm{mM} \mathrm{NaCl}$.

\section{Analytical Ultracentrifugation}

The ultracentrifugation experiments were performed as previously described. ${ }^{12}$

Address reprint requests to Wolfram Welte, Universität Konstanz, Fakultät für Biologie, Universitätsstraße 10, 78434 Konstanz, Germany.

Kay Diederichs' present address is Fakultät für Biologie, Universität Konstanz, 78434, Konstanz, Germany. 


\section{Crystallization}

Crystals were grown using the sitting drop method in microtiter plates. Sitting drops were prepared by mixing $5 \mu \mathrm{l}$ of the porin solution with $5 \mu \mathrm{l}$ of the corresponding reservoir solution. The protein concentration in the crystallization droplets was about $6 \mathrm{mg} / \mathrm{ml}$.

\section{X-Ray Crystallographic Studies}

For X-ray exposure, the crystals were mounted in thin-walled glass capillaries (Mueller, Berlin, Germany). Still and precession photographs were taken with a rotating anode source (Siemens AG, Germany) operated at $35 \mathrm{kV}, 20 \mathrm{~mA}$ and equipped with a precession camera (reciprocal lattice explorer, Stoe, Darmstadt, Germany). Native data sets were collected on a Stoe image plate detector system. The $\mathrm{X}$-ray source was a rotating anode (Stoe) operating at $40 \mathrm{kV}, 100 \mathrm{~mA}$. For data reduction and determination of spacegroups, the XDS program ${ }^{18}$ was used.

\section{RESULTS AND DISCUSSION}

Analysis of the isolated porin by SDS-polyacrylamide gel electrophoresis showed major protein bands at apparent molecular masses of 81 and 33 $\mathrm{kDa}$ after solubilization with sample buffer at room temperature and $100^{\circ} \mathrm{C}$, respectively. In general, the oligomeric species of porins are resistant to SDS denaturation. Incubation in sample buffer at $100^{\circ} \mathrm{C}$ results in the dissociation into monomeric subunits. The porin solution was contaminated by lipopolysaccharide (LPS) as detected by specific silver staining of SDS-gels. ${ }^{13}$ LPS was reported to interfere seriously with crystallization of bacterial porins. ${ }^{14}$ After further purification by anion exchange chromatography less then $1 / 50 \mathrm{~mol}$ LPS per mol of porin were present, according to the detection limit of the silver staining method for R-type LPS. ${ }^{15}$

Monodispersity of the protein-detergent complexes was demonstrated by sedimentation velocity experiments in an analytical ultracentrifuge. Sedimentation equilibrium experiments were performed in order to determine the mass of the native porin. A molecular weight of about 106,000 Da was obtained. Additional estimations with a gel filtation column (Sephacryl S-300, Pharmacia), calibrated with membrane proteins of known masses, and by native polyacrylamide electrophoresis in Triton X-100 were in accordance with a value of about 100,000 Da. With a monomer of $33,000 \mathrm{Da}$ (determined by SDSpolyacrylamide gel electrophoresis) this suggests that the porin forms trimers as typical for bacterial porins. Therefore we cannot verify a dimeric structure of the Paracoccus porin, originally proposed ${ }^{11}$ based on Ferguson plots and chemical cross-linking studies.

To test for native structure, the porin was reconstituted into different asymmetric planar lipid bi- layer systems with and without LPS and into symmetric phospholipid bilayers. ${ }^{16}$ The porin formed general diffusion pores without ion selectivity. The calculated pore diameter of $1.5 \mathrm{~nm}$ is in agreement with earlier estimations by liposome swelling assays. ${ }^{11}$ Furthermore, single channel closing events in three steps are in accordance with a trimeric structure. $^{16}$

A coarse crystallization screening with porin solubilized in various detergents yielded microcrystals in 3 cases, with $0.08 \%$ LDAO, $1.0 \% \beta$ - $d$-octylglucopyranoside (OG), and $0.2 \%$ decylmaltoside (DM) and with polyethylene glycol (PEG) 600 as precipitant. The presence of divalent cations in concentrations from 5 to $200 \mathrm{mM}$ was necessary for crystal growth. For improvement of the crystal size, crystallization parameters such as $\mathrm{pH}$, buffer type, ionic strength, ionic type were optimized. Crystals with dimensions of $200 \times 200 \times 100 \mu \mathrm{m}$ grew in a crystallization buffer containing $20 \mathrm{mM}$ Tris- $\mathrm{HCl}(\mathrm{pH}$ 7.5), $200 \mathrm{mM} \mathrm{KCl}, 10 \mathrm{mM} \mathrm{CaCl}_{2}, 1 \mathrm{mM} \mathrm{NaN}_{3}$, and $1 \%$ OG within a few days. The initial protein solution contained 14 to $18 \%$ (w/v) PEG 600, the reservoir 28 to $32 \%$. Still photographs showed reflections to $4 \AA$ resolution. Crystals obtained in the detergents LDAO or DM showed only poor X-ray diffraction to about $8 \AA$. Further attempts to improve the resolution limit by changing the crystallization parameters or by adding of small amphiphiles ${ }^{17}$ such as $\beta$ - $d$-hexylglucopyranoside or hexyl-(dimethyl)amine oxide were not successful.

Given the importance of divalent cations during crystal growth we made porin preparations without adding EDTA in the two solubilization steps. Initially EDTA had been added with the intention to minimize the interactions between the porin and LPS molecules. The absence of EDTA did not alter the further purification, but obviously affected the quality of the crystals. Reflections were now observed to $3 \AA$.

The crystals belong to the triclinic space group, with unit cell dimensions $a=89.7 \AA, b=98.8 \AA, c$ $=112.5 \AA, \alpha=112.5^{\circ}, \beta=101.8^{\circ}, \gamma=106.7^{\circ}$ (crystal form II). Assuming a molecular weight of $106,000 \mathrm{Da}$ (determined by analytical ultracentrifugation) the crystallographic asymmetric unit contains 2 trimers, with a resulting Matthews parameter $V_{\mathbf{M}}$ of $3.9 \AA^{3} / \mathrm{Da}$. When crystallization was conducted in the presence of $10-15 \%$ of PEG 400 or PEG 200 in the protein solution under otherwise identical conditions as above we obtained monoclinic crystals of the space group $C 2$ (crystal form I, Fig. 1) with the same diffraction limit. The unit cell parameters are $a=112.2 \AA, b=193.8 \AA, c=100.5$ $\AA$, and $\beta=129.2^{\circ}$ ). The asymmetric unit contains one trimer (calculated $V_{\mathrm{M}}=3.9 \AA^{3} / \mathrm{Da}$ ).

In view of the close relationship between Rhodobacter capsulatus and Paracoccus denitrificans revealed by $16 \mathrm{~S}$ rRNA homology, ${ }^{19}$ we are try- 


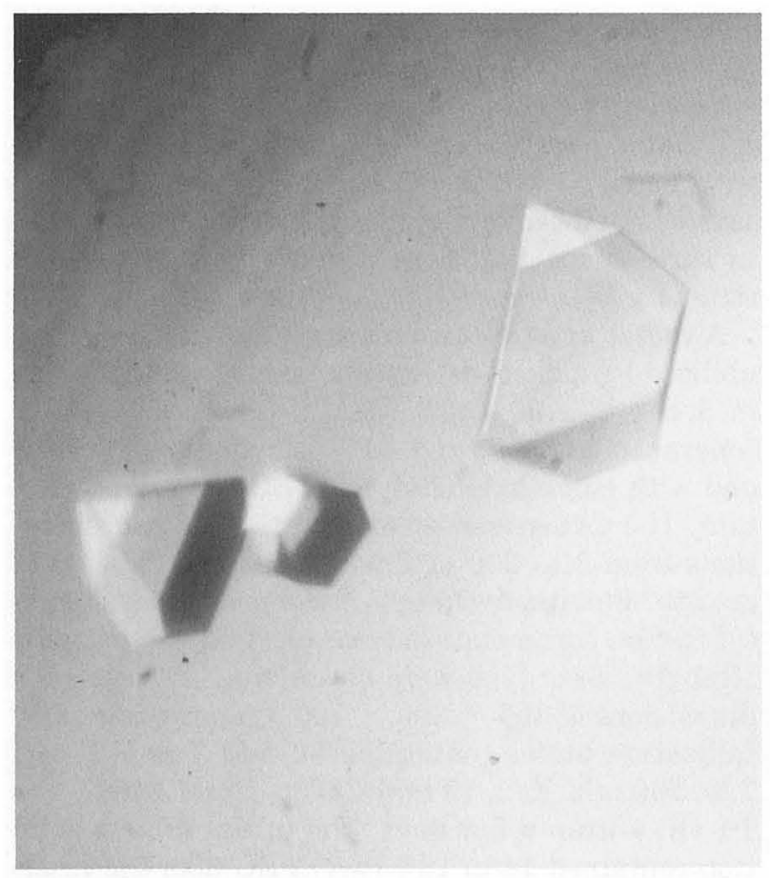

Fig. 1. Monoclinic crystals of Paracoccus denitrificans porin (form I). The crystals were grown using the sitting drop method. The reservoir conditions were $28 \%$ PEG $600,10 \%$ PEG 200, 20 $\mathrm{mM}$ Tris- $\mathrm{HCl} 7.5,200 \mathrm{mM} \mathrm{KCl}, 10 \mathrm{mM} \mathrm{CaCl}_{2}, 1 \mathrm{mM}$ sodium azide, $1 \%$ OG. The maximal size observed was $250 \times 250 \times 100 \mu \mathrm{m}$.

ing to solve the structure by molecular replacement methods based on a model derived from the highresolution structure of porin from $R$ hodobacter capsulatus. ${ }^{2}$

\section{ACKNOWLEDGMENTS}

We thank Ariel Lustig, Biozentrum Basel, Switzerland for carrying out the analytical ultracentrifuge experiments.

\section{REFERENCES}

1. Nikaido, H. Porins and specific channels of bacterial outer membranes. Mol. Microbiol. 6:435-442, 1992

2. Weiss, M.S., Kreusch, A., Schiltz, E., Nestel, U., Welte, W., Weckesser, J., Schulz, G.E. The structure of porin from
Rhodobacter capsulatus at $1.8 \AA$ resolution. FEBS Lett. 280:379-382, 1991

3. Cowan, S.W., Schirmer, T., Rummel, G., Steiert, M., Ghosh, R., Pauptit, R.A., Jansonius, J.N., Rosenbusch, J.P. Crystal structures explain functional properties of two $E$. coli proteins. Nature (London). 358:727-733, 1992.

4. Kreusch, A., Neubüser, A., Schiltz, E., Weckesser, J., Schulz, G.E. Structure of the membrane channel porin from $R$ hodopseudomonas blastica at $2.0 \AA$ resolution. Protein Sci. 3:58-63, 1994.

5. Schirmer, T., Keller, T.A., Wang, Y.-F., Rosenbusch, J.P. Structural basis for sugar translocation through maltoporin channels at $3.1 \AA$ resolution. Science $267: 512-514$, 1995.

6. Wilson, D.B. Cellular transport mechanism. Annu. Rev. Biochem. 47:933-965, 1978.

7. Nikaido, H., Saier, M.H. Jr. Transport proteins in bacteria: Common Themes in their design. Science 258:936-942, 1992.

8. Blachly-Dyson E., Peng, S., Colombini, M., Forte, M. Selectivity changes in site-directed mutants of the VDAC ion channel: structural implications. Science 247:1233-1236, 1990.

9. John, P., Whatley, F.R. Paracoccus denitrificans and the evolutionary origin of the mitochondrion. Nature (London) $254: 495-498,1975$.

10. John, P., Whatley, F.R. Paracoccus denitrificans Davis (Micrococcus denitrificans Beijerinck) as a mitochondrion. Adv. Bot. Res. 4:51-115, 1977.

11. Zalman, L.S., Nikaido, H. Dimeric porin of Paracoccus denitrificans. J. Bacteriol. 162:430-433, 1984.

12. Holzenburg, A., Engel, A., Kessler, R., Manz, H.J., Lustig, A., Aebi, U. Rapid isolation of ompF porin-LPS complexes suitable for structure-function studies. Biochemistry 28 : $4187-4193,1989$

13. Tsai, C.-M., Frasch, C.E. A sensitive silver stain for detecting lipopolysaccharides in polyacrylamide gels. Anal. Biochem. 119:115-119, 1982.

14. Garavito, M., Rosenbusch, J.P. Isolation and crystallization of bacterial porin. Methods Enzymol. 125:309-328, 1986.

15. Parr, T.H., Poole, K., Crockford, G.W.K., Hancock, R.E.W. Lipopolysaccharide-free Escherichia coli OmpF and $P$ seudomonas aeruginosa protein $\mathrm{P}$ are functionally active in lipid bilayer membranes. J. Bacteriol. 165:523-526, 1986.

16. Wiese, A., Schröder, G., Brandenburg, K., Hirsch, A., Welte, W. and Seydel, U. Influence of the lipid matrix on incorporation and function of LPS-free porin from Paracoccus denitrificans. BBA 1190:231-241, 1994.

17. Michel, H. Crystallization of membrane proteins. Trends Biochem. Sci. 8:56-59, 1983.

18. Kabsch, W. Evaluation of single-crystal X-ray diffraction data from a position-sensitive detector. J. Appl. Cryst. 21: 916-924, 1988.

19. Fox, G.E., Stackebrandt, E., Hespell, R.B., Gibson, J., Maniloff, J., Dyer, T.A., Wolfe, R.S., Balch, W.E., Tanner, R.S., Magrum, J., Zablen, L.B., Blakemore, R., Gupta, R., Bonen, L., Lewis, B.J., Stahl, D.A., Luehrsen, K.R., Chen, K.N., Woese, C.R. The phylogeny of prokaryotes. Science 209:457-463, 1980. 